\title{
DETERMINATION OF AGE BY STUDY OF CLOSURE OF ENDOCRANIAL SUTURES
}

\author{
Gokula Ramanan ${ }^{1}$, Sangeetha Ranganathan², Saravanan Ranganathan ${ }^{3}$
}

${ }^{1}$ Associate Professor, Department of Forensic Medicine, Govt. Mohan Kumaramangalam Medical College Hospital, Salem, Tamilnadu. ${ }^{2}$ Assistant Professor, Department of Forensic Medicine, Govt. Mohan Kumaramangalam Medical College Hospital, Salem, Tamilnadu. 3Tutor, Department of Pharmacology, Annapoorna Medical College and Hospital, Salem, Tamilnadu.

ABSTRACT
BACKGROUND
Skull is the best preserved remains of the recovered skeleton that resists putrefaction and not easily destroyed. If determination
of age by means of study of endocranial closure of suture can give a precise result, it could be a reliable method in criminal cases
such as rape, murder and criminal responsibility. Other methods available to determine the age of the individual can only be
determined by the age in decades.

\section{OBJECTIVES}

The objectives of the present study were to observe the chronology and pattern of endocranial suture closures - sagittal, coronal and lambdoid suture; to determine the correlation between closure of endocranial suture and age. Further, we would like to find the bilateral and bisexual variation in closure of endocranial sutures.

\section{MATERIALS AND METHODS}

Our study was conducted in 100 cases of age above 20 years. Acsadi-Nemeskeri scale of suture closure was used to assess the age after removing the calvaria by craniotome. Scale of endocranial suture closure from 0-4 was observed in 16 parts as done by Acsadi-Nemeskeri. The observations were analysed using SPSS 11.5 statistical software.

\section{RESULTS}

Endocranial fusion of sagittal, coronal and lambdoid suture, starts eventually between 20 and 29 years of age. Completion of suture closure occurs between 60 and 69 years in case of sagittal suture and between 50 and 59 years in case of coronal and lambdoid suture. There is no significant sexual variation and bilateral variation in endocranial suture closure.

\section{CONCLUSIONS}

Correlation between endocranial closure of suture and age is observed up to 50 years of age, but after 50 years there is no significant correlation. There is no bilateral variation in suture closure of lambdoid suture. Coronal suture closes earlier to sagittal and lambdoid suture endocranially. The endocranial closure of suture with respect to age is erratic and not suitable for precise estimation of age.

\section{KEYWORDS}

Endocranial Sutures, Coronal, Sagittal, Lambdoid.

HOW TO CITE THIS ARTICLE: Ramanan G, Ranganathan S, Ranganathan S. Determination of age by study of closure of endocranial sutures. J. Evolution Med. Dent. Sci. 2016;5(46):2860-2864, DOI: 10.14260/jemds/2016/667

\section{INTRODUCTION}

Identification is nothing but recognition of an individual by means of various physical features and biological parameters. There are a number of established parameters for identification of an individual such as birth marks, scar, tattoo marks, malformations, personal features, anthropometric measurements, finger prints and foot prints, DNA finger printing. ${ }^{1,2}$ Problem of identification comes in everyday medico-legal practice, both in civil and criminal cases. The bones as they resist putrefaction and cannot be destroyed by animals, they can lead to the reliable determination of race, age, sex of the individual.

The use of cranial sutures for age estimation is a matter of considerable debate and its reliability has not been

Financial or Other, Competing Interest: None.

Submission 22-04-2016, Peer Review 19-05-2016,

Acceptance 23-05-2016, Published 07-06-2016.

Corresponding Author:

Dr. Gokula Ramanan,

Associate Professor

Department of Forensic Medicine,

Govt. Mohan Kumaramangalam Medical College Hospital,

Salem, Tamilnadu, India.

E-mail: gokularamanan2016@gmail.com

DOI: $10.14260 /$ jemds $/ 2016 / 667$ demonstrated conclusively by various researchers. The significance of determination of the age is most important in the criminal cases such as rape, prostitution, kidnapping, infanticide, juvenile delinquency and criminal responsibility.

The texture of a young adult skull is smooth on both the inner and outer surfaces. ${ }^{3}$ (Krogman 1962:88). Cranial morphological age sequencing provided by Krogman: 1) Starting from 25 years of age, muscular markings become increasingly evident particularly on the occipital, temporal and lateral sides of the mandible; 2) Between 35 to 45 years, the surface gives a matted, granular appearance; 3) Around 35 to 45 years, inside of skull shows the Pacchionian depressions and occur with much more frequency; 4) After 50 years of age, the diploe become less vascular channelled and there is an increasing replacement by bone. The suture closure begins endocranially and proceeds ectocranially. In many cases, complete closure will eradicate any evidence of cranial sutures.

The method of age determination by studying the cranial suture closure has been more commonly used, because skull is the best preserved remains of the recovered skeleton. ${ }^{4}$ Age determination by cranial suture closure is based upon the hypothesis that suture closure is part of the aging process. The work of Todd during the 1920s provided anthropologists with 
a framework for estimating age of death from both the cranial sutures and the pubic symphysis. ${ }^{5-8}$ During the 1970 s through to the 1990s, several researchers studied the cranial sutures for the purpose of determining adult age at death. ${ }^{9-12}$

According to Hershkovitz et al (1997). ${ }^{13}$ standard aging methods based on suture closure make use of two arbitrary assumptions: 1) That the different degree of suture closure (Usually four stages) represents a normal progressive process, and 2) That different ontogenetic processes operate in different segments of the same suture. Hershkovitz et al believes that these assumptions have no factual basis and more than one-fifth of skulls do not follow the classic pattern of sutural segmentation.

The objective of the present study is to observe the chronology and pattern of union of endocranial sutures namely coronal, sagittal and lambdoid etc., to detect bilateral and bisexual variations in endocranial suture closure if any, to specify the relationship between progression of union of endocranial suture and age of the subject to formulate a practical method of estimation of age by studying the progression of the closure of cranial sutures.

\section{MATERIALS AND METHODS}

The study was conducted on medico-legal post-mortem examination cases at Institute of Forensic Medicine, Madras Medical College, Chennai, over a period of one year.

\section{Inclusion Criteria}

1. The cases of known age coming for medico-legal postmortem examination. Age was confirmed by documentary evidences like birth certificate, identification cards, ration card, etc.

2. Subjects of more than 20 years of age were taken.

\section{Exclusion Criteria}

1. Unknown, unclaimed bodies where exact age cannot be confirmed.

2. Cases showing deformed or diseased or fractured skull, which may hamper the study of suture closure.

\section{METHODOLOGY}

100 cases of age 20 and above were studied. Documentary proof of age was collected. After reflecting the scalp, coronal, sagittal, lambdoid sutures were studied applying AcsadiNemeskeri scale endocranially, after removing the calvaria by craniotome taking due care to include complete coronal and sagittal suture. Lambdoid suture was studied in-situ. The calvarium was cleaned of soft tissues and was dried, which made the sutures more prominent. The obliteration of the sutures was ascertained endocranially. Degree of closure was scored in 16 parts of the main cranial sutures as done by Acsadi-Nemeskeri.14

The coronal suture was studied in three parts on right and left side each; sagittal suture in four parts and lambdoid sutures in three parts each on right and left side. Endocranial sutures were simply divided in sections of equal length.

\section{SCALE FOR CLOSURE}

\section{Acsadi-Nemeskeri Complex Method}

- $0=0$ pen. There is still little space left between edges of adjoining bones.
- $\quad 1=$ =ncipient closure. Clearly visible as a continuous often zigzagging line.

- 2=Closure in process. Line thinner, less zigzags, interrupted by complete closure.

- $\quad 3=$ Advanced closure. Only pits indicate where the suture is located.

- $\quad 4=$ =Closed. Even location cannot be recognized.

Mean endocranial closure stages were calculated for the three main sutures by adding the scored closure stages of the different sections and dividing the result by number of sections which compose the suture in question.

\section{Statistical Methods}

To estimate the possible relation between suture closure and age at death, appropriate statistical tools were used (Spearman rank correlation coefficients, Levene's test for equality of variances, student's test for equality of means, SPSS 11.5 version software). $\mathrm{P}<0.05$ was considered as significant.

\section{RESULTS}

\section{Age and Sex Distribution}

The age of the victims varied from 20 to 90 years. Age groups were classified as 10-year interval, so as to compare with the previous studies. Out of 100 cases, it was observed that maximum number of cases were in 20-29 age group, which also tells us regarding the age distribution of cases coming for autopsy in MMC, Chennai.

There were 38 cases ( 28 male and 10 female) between the age group 20-29, 25 cases ( 17 male and 8 female) between 30 39,10 cases ( 8 male and 2 female) between $40-49,11$ cases ( 8 male and 3 female) between 50-59, 10 cases (7 male and 3 female) between 60-69, and 6 cases ( 4 male and 2 female) were above 70 years of age. The minimum age of case is 20 and maximum age is 90 , mean age is 38.36 . Standard deviation is 16.794 and median age is 34.50 . Males constituted a majority of $72 \%$ cases compared to females who were only $28 \%$. When comparison between male and female subjects were made, females have late closure; mean for total cases was 8.99 vs 7.32 (except in 20-29 age groups where closure was seen earlier in females (Table 1)).

\section{Endocranial Closure of Sutures}

Sagittal suture, endocranially starts fusing at the age of 20-29 years. More or less complete union with scale score $>3$ is attained at 40-49 age group (Mean 3.10, maximum 3.30 for S4). It is totally fused by the age of 60-69 years (Mean value 3.65).

In coronal suture near complete closure occurs by the age of 40-49 age and total closure occurs by 50-59 years. (Mean value 3.10 in $40-49$ years and 3.55 in 50-59 years).

Lambdoid suture starts fusing during 20-29 age group and closes by 40-49 years, but the complete closure occurs during $50-59$ years. (Mean values are $0.76,3.06,3.23$ respectively for 20-29, 40-49 and 50-59).

Overall coronal suture closes earlier followed by sagittal and lambdoid suture endocranially. (Mean values 2.18, 2.13 and 2.10). In sagittal suture, S3 (pars obelica) closes earlier than other parts. S3 closes early followed by S4, S1 and S2. (Mean value 2.29, 2.20, 2.03 and 2.00). In coronal suture, C2 (pars complicata) closes earlier than $\mathrm{C} 1$ and C3 (mean value 2.17, 2.15 and 2.15). In lambdoid suture, L3 (pars estetica) 
closes earlier followed by L2 (pars intermedia) and L1 (pars lambdica). (Mean value of 2.16, 2.05 and 2.04).

\section{Bilateral Variation of Sutures}

In coronal sutures there was minor difference in closure among right and left side endocranially, which can be safely ignored. When sexes were taken separately also, there were minimal difference bilaterally. In lambdoid suture also, there were no difference in closure between right and left side. Right and left side of coronal and lambdoid sutures were compared endocranially; there were no significant difference after applying student test $(\mathrm{p}>0.05)$. It implies that there is no bilateral variation in endocranial suture closure.

\section{Sexual Variation in Endocranial Closure of Sutures}

When males-to-female comparison were made for sagittal, coronal and lambdoid sutures, there was no significant correlation (applying Levene's test for equality of variances, $(.836, .770, .897)$ ) ( $p$ value $>0.05)$ found. It implies that there is no significant difference in sex in union of sutures in all age groups.

\begin{tabular}{|c|c|c|c|c|c|c|}
\hline $\begin{array}{c}\text { Age } \\
\text { Group }\end{array}$ & \multicolumn{1}{|c|}{$\mathbf{N}(\mathbf{m} / \mathbf{f})$} & \multicolumn{2}{c|}{ Mean(m/f) } & \multicolumn{2}{c|}{$\begin{array}{c}\text { Std } \\
\text { Deviation(m/f) }\end{array}$} \\
\hline $20-29$ & 28 & 10 & 2.93 & 4.50 & 3.516 & 3.979 \\
\hline $30-39$ & 17 & 8 & 11.06 & 5.00 & 4.337 & 5.014 \\
\hline $40-49$ & 8 & 2 & 12.50 & 12.00 & 3.381 & 0.000 \\
\hline $50-59$ & 8 & 3 & 13.38 & 8.00 & 3.249 & 6.928 \\
\hline $60-69$ & 7 & 3 & 15.14 & 13.33 & 2.268 & 4.619 \\
\hline$>=70$ & 4 & 2 & 16.00 & 16.00 & 0.000 & 0.000 \\
\hline Total & 72 & 28 & 8.99 & 7.32 & 6.092 & 5.722 \\
\hline \multicolumn{6}{|c|}{ Table 1: Age Distribution of Cases Studied for } \\
Endocranial Suture Closure \\
\hline
\end{tabular}

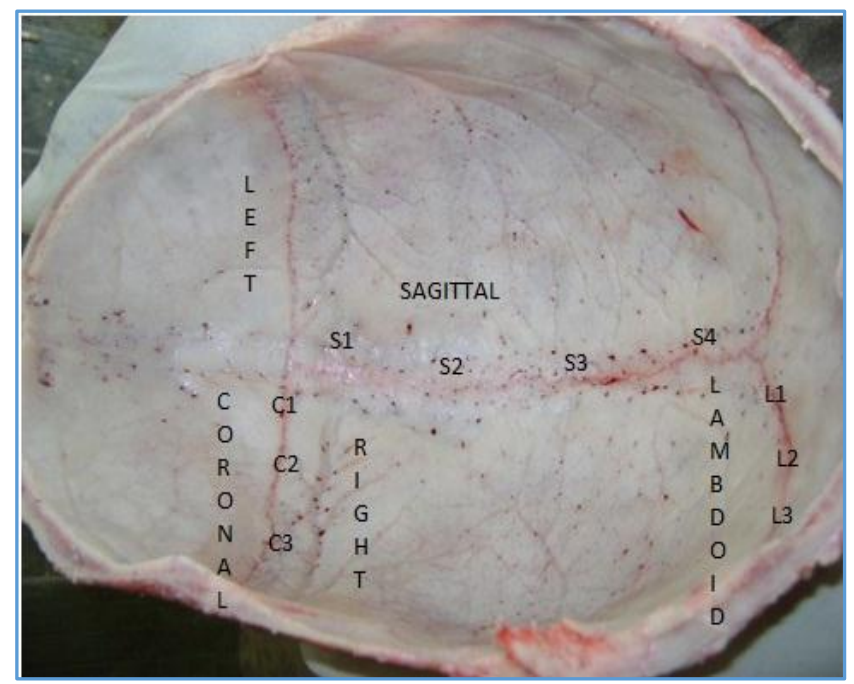

Sagittal: S1-3, S2-3, S3-2, S4-2. Coronal: C1-2, C2-2, C3-2. Lambdoid: L1-2, L2-2, L3-2

Fig. 1: Grading of Endocranial Suture Closure of 29-YearOld Female using Acsadi-Nemeskeri Scale

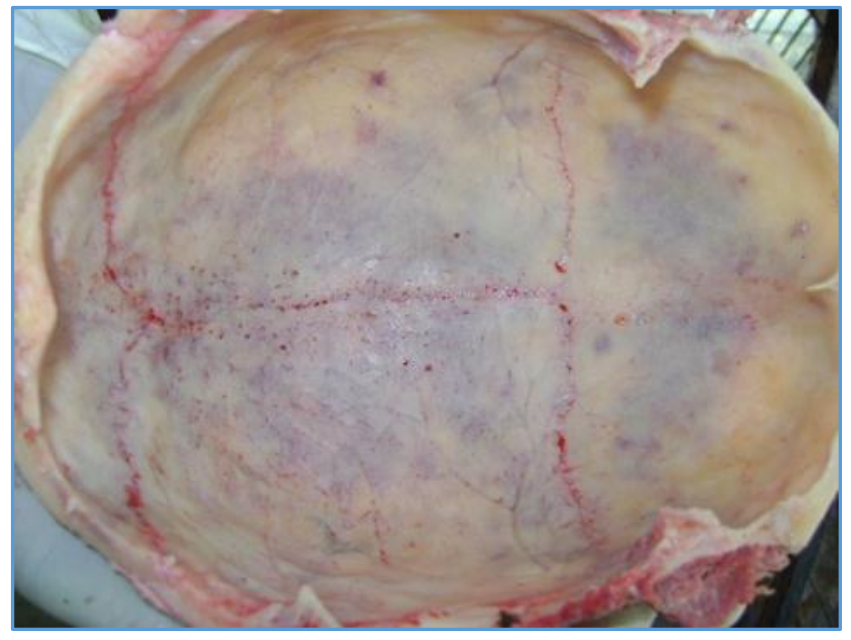

Sagittal: S1-2, S2-2, S3-3, S4-3 Coronal: C1-2, C2-2, C3-2. Lambdoid-LR1-3, LR2-3, LR3-2, LL1-2, LL2-2, LL3-2

Fig. 2: Grading of Endocranial Suture Closure of 34-YearOld Male using Acsadi-Nemeskeri Scale

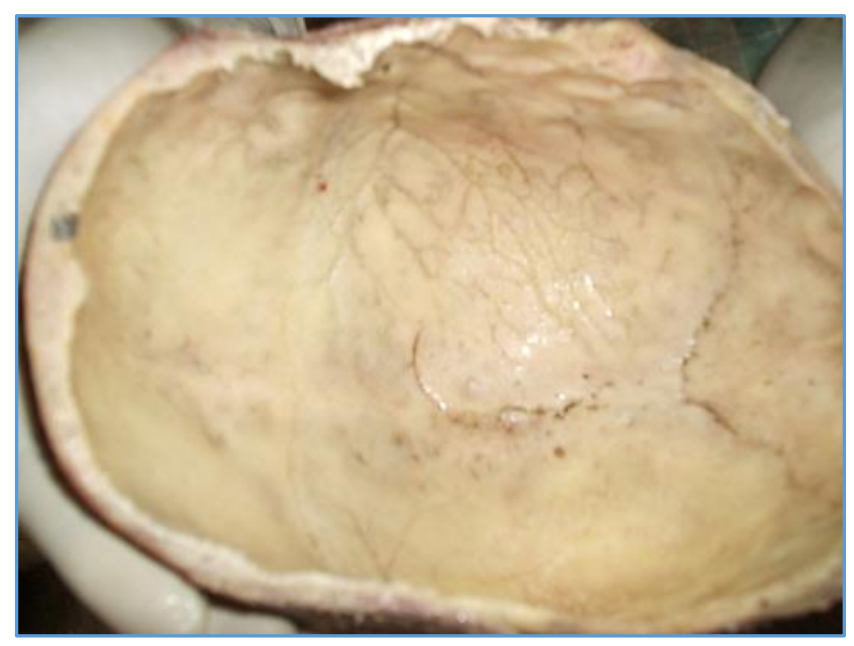

Sagittal: S1-4, S2-4, S3-3, S4-4. Coronal: C1-4, C2-4, C3-4. Lambdoid: L1-3, L2-3, L3-3

Fig. 3: Grading of Endocranial Suture Closure of 47 Year old Male using Acsadi-Nemeskeri Scale

\section{DISCUSSION}

In later years of life when all the teeth have erupted, practically all the epiphyses have united with the diaphysis, the height and weight are of no significance to determine the age. Literature review shows certain changes such as lipping of the bones, greying of the hair, appearance of arcus senilis in the cornea, opacity in lens, atherosclerotic changes in the arteries, wrinkling of the skin especially of the face are due to aging process, but they are too vague to be considered for determination of age in Medico-legal work.

Obliteration of skull sutures in late age practically when all the teeth have erupted and epiphysis have fused, i.e. after 21 years of age, gives a fairly accurate idea that however determination of age can only be in decades based on sole criteria of suture obliteration. 


\section{Sagittal Suture}

In our present study we have found that the sagittal suture starts fusing endocranially at the between 20-29 years and completion is perfected at the age of 60-69 years, and this observation conforms with that reported by Todd \& Lyon. ${ }^{5}$ (1924), while it is in contrast to the observation reported by Pommerol.15 (1869), and Topinard.16 (1885), who indicated endocranial commencement of sagittal suture at a much later age at about 40 years. These latter workers have reported on very scanty specimens, so it cannot be considered as authentic.

\section{Coronal Suture}

Endocranial fusion of coronal suture was observed as early as 20-29 years and completion by the age of 50-59 years, other workers like Topinard.15 (1885) reported closure between 4050 years. Their study does not indicate whether it was ectocranial or endocranial or it was commencement or termination.

\section{Lambdoid}

Lambdoid endocranially starts fusing at the age of 20-29 years in the present context, which shows that it is a year earlier than that reported by Todd and Lyon. ${ }^{5}$ (1924), while completion in our study is 50-59 years. The other workers have not reported on lambdoid suture. Indian data on Endocranial suture closure correlate well with those of the male whites. ${ }^{6}$ (Todd \& Lyon 1925). Negro skulls however show an early commencement and closure.

All the previous work was done in France, Germany and United States of America, under different climatic conditions and in diverse racial groups. Though consensus of opinion in our country is that the obliteration of the skull sutures in females is earlier than that of males, in the present study no substantial difference was noticed. This finding is in conjunction with Meindl and Lovejoy. 4

Perizonius. ${ }^{16}$ studies the time of suture closure in 174 male and 82 female skulls of non-Jewish inhabitants of Amsterdam whose ages were between 20 and 99 years. He examined the sutures endocranially by introducing a small lamp through the foramen magnum. He did not find any difference in the time of closure of the sutures in two sexes or on the two surfaces. According to him, the obliteration of sutures was related to age in the age group of 20-49 years but not thereafter. Validity of his observations is questionable, as it is not possible to observe the lateral parts of the lambdoid sutures endocranially by the procedure followed by him.

\section{CONCLUSIONS}

1. There is some correlation between endocranial suture closure and age up to 50 years' age group, thereafter there is no significant correlation. Any attempt to derive a reliable formula to estimate the age from score of suture closure was met with failure for the following reasons: 1 ) The trend of correlation is neither increasing nor decreasing with age; 2) The sample size is too small to derive a formula; 3) Unequal distribution of males and females in the study sample.

2. Though there is some difference in suture closure in males and females, it is not significant statistically. (Females showed earlier union than males in the age group 20-29, in the other age groups suture closure occurred earlier in males).
3. There is no significant variation in suture closure of right and left sides of coronal and lambdoid sutures.

4. Endocranially: Coronal suture closes earlier followed by sagittal and lambdoid.

5. Within sagittal suture segment, pars obelica (S3) closes earlier followed by pars lambdica (S4), pars vertices (S2), pars bregmatica (S1). In the coronal suture, pars complicate (C2) unites earlier followed by pars bregmatica (C1) and pars pterica (C3). In lambdoid suture pars asterica (L3) closes earlier followed by pars intermedia (L2) and pars lambdica (L1).

6. Endocranial union starts at 20-29 age groups, but progression is not uniform. Complete closure (mean value $>3.5$ ) of sagittal and lambdoid sutures occurs in the age group of 60-69 years, whereas in the coronal it occurs by 50-59 years.

7. Although cross-sectional in nature, suture obliteration patterns (Totally open, totally closed, partially open and partially closed) are not temporary progressive stages on an age scale, but rather independent and permanent phenomena.

8. Commencement and complete obliteration of a segment of the entire suture is so erratic that it is not amenable for estimating the age.

\section{REFERENCES}

1. Vij K. Identification. In: textbook of forensic medicine and toxicology principles and practises. Elsevier, 2005;p 5063.

2. Reddy KSN. Identification. In: the essentials of forensic medicine and toxicology. Jaypee brothers medical publishers, 2005;p 67-8.

3. Skeletal age: earlier years, skeletal age: later years 1 . Suture closure and skeletal age. In the human skeletal in forensic medicine. Thomas CC, 1962;1st ed:18-71, 76-89, 92-111.

4. Meindl RS, Lovejoy CO. Ectocranial suture closure: a revised method for the determination of skeletal age at death based on the lateral anterior sutures. Am J Phys Anthropol 1985;68(1):57-66.

5. Todd TW, Lyon DW. Endocranial suture closure its progress and age relationship part 1 adult males of white stock. Am J Phys Anthropol 1924;7(3):325-84.

6. Todd TW, Lyon DW. Suture closure its progress and age relationship part 4 ectocranial closure in adult males of negro stock. Am J Phys Anthropol 1925;8(2):149-68.

7. Todd TW, Lyon DW. Cranial suture closure, its progress and age relationship part 2 ectocranial closure in adult males of white stock. AJPA 1925;8(1):23-45.

8. Todd TW, Lyon DW. Cranial suture closure, its progress and age relationship part 3 endocranial closure in adult males of negro stock. AJPA 1925;8(1):47-71.

9. Johnson JS. Comparison of age estimation using discriminant function analysis with some other age estimations of unknown skulls. Journal of Anatomy 1976;121(3):475-84.

10. Masset C. Age estimation on the basis of cranial sutures. In: Işcan MY (ed). Age markers in the human skeleton. Springfield, IL: Thomas CC 1989;71-103.

11. Key CA, Aiello LC, Molleson T. Cranial suture closure and its implications for age estimation. International Journal of Osteoarchaeology 1994;4:193-207. 
12. Nawrocki S. Regression formulae for estimating age at death from cranial suture closure. In: Reichs $K$ (ed). Forensic osteology: advances in identification of human remains Springfield IL, Thomas CC 1998;2nd ed:276-92.

13. Hershkowitz I, Latimer B, Dutour O, et al. Why do we fail in aging the skull from the sagittal suture? Am J Phys Anthropol 1997;103(3):393-9.

14. Acsadi G, Nemeskeri J. History of human life span and mortality. Akademiai kiado 1970;p 311-32.
15. Topinard P. Eléments d'santhropologie générale. Paris 1885;8(1):14-7.

16. Perizonius WRK. Closing and non-closing sutures in 256 crania of known age and sex from Amsterdam (AD 18831909). Journal of Human Evolution 1984;13(2):201-16. 